\title{
ENIGMA DO ESPAÇO: \\ FENOMENOLOGIA E ONTOFENOMENOLOGIA DA PROFUNDIDADE EM M. MERLEAU-PONTY
}

Luís António Umbelino

Universidade de Coimbra

\section{A Estrutura da Percepção}

Data de 1933 o "projecto de trabalho sobre a natureza da percepção" no qual Merleau-Ponty esboça pela primeira vez o intento de meditar, "no estado presente da neurologia, da psicologia experimental (particularmente da psicopatologia) e da filosofia", o "problema da percepção e particularmente da percepção do corpo próprio".' Tal projecto tem um cunho crítico, já que os desenvolvimentos verificados em tais campos disciplinares, ao lançarem sobre a questão da percepção uma luz nova, obrigam a refundar muitas das noções tradicionais com as quais se enfrentou o tema.

Assim, a aplicação dominante das ideias directrizes do criticismo ao contexto da psicologia e filosofia da percepção, desde logo, parecem não resistir ao confronto com os dados experimentais da Gestalttheorie, que vêm demonstrar não ser a percepção uma operação intelectual e concluir não se poder considerar os dados sensíveis como "matéria" incoerente e distinta de uma "forma" intelectual. Por outro lado, os desenvolvimentos da neurologia, ao precisarem o papel do sistema nervoso, colocaram em evidência o enraizamento da percepção num "quadro motor", 2 deste modo descartando a ideia de que as ligações entre dados visuais e musculares, por exemplo, seriam estabelecidos por uma actividade cognitiva ordenadora. A "literatura recente sobre a «percepção do corpo próprio»", confirma, por seu turno, a necessidade de remeditar a per-

1 Cf. Merleau-Ponty, M., Le primat de la perception et ses conséquences philosophiques. Lagrasse: Verdier, 1996, p. 11 (=PP)

2 PP, p. 12. 
cepção a partir do "sensível e do concreto" e de a colocar a salvo das reduções intelectualistas sem, no entanto, a assimilar ao objectivismo estrito do universo científico. ${ }^{3}$ Tais considerações são tanto mais importantes quanto sabemos que, para Merleau-Ponty, a percepção não é encarada como simples questão "técnica" ou "regional". Na percepção joga-se a questão radical de saber como pode o nosso "perceber" chegar a ser "perceber de alguma coisa"; ou seja, na percepção joga-se a própria questão fundadora da abertura e ligação ao que $h a{ }^{4}{ }^{4}$ Os dados recolhidos das várias disciplinas indicadas devem, pois, contribuir para uma compreensão renovada da percepção; as demonstrações que apresentam devem ser interpretadas a fim de nelas se reconhecerem indicações ou informações que apontam para determinadas ideias que a filosofia, por seu lado, deve desenvolver num conjunto articulado, aprofundado e radical, assim libertando as respectivas implicações mais decisivas.

Tal será o intento de Merleau-Ponty, logo a partir das primeiras linhas de La Structure du comportement, onde apresenta como problema regulador da sua investigação o das "relações entre consciência e natureza". 5 Ante tal questão, uma tarefa é, desde logo, exigida: apontar os limites evidentes dos dois paradigmas de pensamento predominantes - seus contemporâneos-que se mostraram incapazes de pensar a conexão entre os seus elementos. Por um lado, o pensamento criticista (neokantiano) que se caracteriza por conceber a natureza como um conjunto de "relações objectivas constituídas pela consciência" e que tanta influência exercerá sobre a física; por outro lado, o pensamento causal, patente sobretudo na biologia e na psicologia, e que privilegia as relações de determinação causal recíproca entre diferentes "ordens de realidade" (o psicológico é efeito do fisiológico; determinado comportamento efeito de factores ambientais, etc.), assim acabando por conceber a consciência como um objecto natural condicionado (numa relação de causa/efeito) pelo meio. Segundo a primeira perspectiva, a natureza recebe o seu carácter objectivo (e ideal) da capacidade sintética de uma consciência independente dos eventos empíricos; no segundo caso, a consciência não é mais do que um dos eventos determinados pelas leis que preenchem a natureza. Ora, para Merleau-Ponty, tais pontos de vista são por igual insatisfatórios, pois sob a aparência das respostas que aportam mais não oferecem do que pressupostos e opções teóricas não demonstradas, não criticadas e não sustentadas, que apenas contribuem para desmembrar a relação que importa, justamente, esclarecer. Tais doutrinas afastam-se demasiado rapidamente da necessária descrição minuciosa, fiel e

${ }^{3}$ Cf. $P$ P, p. 13

${ }^{4}$ Cf. Barbaras, R., Le désir et la distance. Introduction à une phénoménologie de la perception. Paris: Vrin, 1999, p. 9.

${ }^{5}$ Mereleau-Ponty, M., La structure du comportement (1942). Paris: PUF, Quadrige, 1990, p. 1 $(=S C)$. 
livre de pressupostos, do topos onde a relação entre consciência e natureza se encontra concretamente realizada: o comportamento. ${ }^{6}$

Tal necessário esforço de fidelização exclusiva aos dados fornecidos pela descrição não é, no entanto, tarefa fácil. Outrossim, exige uma renovada atitude transcendental. É munido de tal atitude que Merleau-Ponty se proporá avaliar os limites claros do realismo empírico reducionista de cunho experimental (causal), bem ilustrado pela reflexologia pavloviana. Tal paradigma é ferido de dúvida pela Gestalttheorie, cujas experiências vêm provar que o comportamento de um ser vivo não se reduz a uma soma de reacções elementares e mecanicamente determinadas a estímulos - proprioceptivo e extereoceptivos - isolados. ${ }^{7}$ Deve reconhecer-se, pelo contrário, que um qualquer estímulo age realmente sobre um organismo ao ser "acolhido" como tendo um qualquer valor vital - por integração, portanto, numa situação típica vivida que tenha para tal organismo um significado geral. A reacção alberga já, neste sentido, uma "inteligibilidade imanente" que a afasta da mera reacção automática a uma causa pontual; mais, tal reacção liga-se "interiormente" à situação vivida, representando, enquanto modo de actividade do próprio organismo, uma efectiva co-respondência a uma forma envolvente. ${ }^{8}$ A harmonização entre a assimilação de estímulos e a estrutura com a qual cada organismo "está" no mundo não permite, no entanto, concluir que o comportamento se possa esgotar, como gostaria o "idealismo de muitos filósofos", num conjunto de encadeamentos reflexos organizados por sínteses cognitivas, à maneira de uma consciência separada da vida e soberana construtora da adequação significativa aos estímulos. Ao invés, Merleau-Ponty constata que o comportamento é uma Gestalt que põe em jogo, em cada situação, núcleos de significação coordenados por capacidades perceptivas; mas esta coordenação, precisamente, acolhe directamente as coisas e acontecimentos do mundo, ou seja, deve concluir-se que existem estruturas cujo sentido percebido é inerente aos dados sensíveis. Nessa Gestalt, pois, as unidades signifiçativas não são constituídas por qualquer subjectividade inclusa, mas são, de pleno direito, modos de aparecer fenoménico que desvendam directamente o mundo; mas, precisamente, não o desvendam como

${ }^{6} S C$, p. 2.

${ }^{7}$ Cf. SC, cap. I, pp. 5 ss. Merleau-Ponty resume assim o essencial: «La réflexologie de.Pavlov traite le comportement comme une chose, l'insère et le résorbe dans le tissu des événements et des relations d'univers [...]. La notion équivoque de stimulus se dédouble à l'analyse: elle retrouve et confond l'événement physique tel qu'il est en soi et d'autre part la situation telle qu'elle est 'pour l'organisme', seule décisive dans les réactions de l'animal.» Veja-se igualmente p. 139

${ }^{8}$ Cf. SC, p. 140. «L'expérience dans un organisme n'est pas l'enregistrement et la fixation de certains mouvements réellement accomplis: elle monte des aptitudes, c'est-à-dire le pouvoir général de répondre à des situations d'un certain type par des réactions variées qui n'ont de commun que le sens. [...] Situation et réaction se relient intérieurement par leur participation commune à une structure où s'exprime le mode d'activité propre de l'organisme.» 
conjunto de objectos isolados e frontais, mas como acontecimento expressivo que se desenrola no próprio uso que cada organismo consegue fazer da sua vida. Entre as variáveis que suscitam as aptidões do organismo para "estar" no mundo, entra em jogo uma "relação de sentido", uma "relação intrínseca": 9 a acção do mundo sobre um organismo exprime já as leis interiores desse organismo, e cada resposta do organismo ao meio resume já a correlação interior que mantém com a natureza.

A noção de forma resume, com aparente justeza, a correlação dialéctica ${ }^{10}$ que une organismo e meio, devendo com proveito aplicar-se à ordem física, vital e humana. Integrando-as "como três tipos de estruturas", tal noção permite suplantar "as antinomias do materialismo e do espiritualismo, do materialismo e do vitalismo", ${ }^{11}$ finalismo ou animismo. E no que concerne à "ordem humana" em particular, as implicações de tal alargamento da análise são enormes: tal ordem deve ser entendida "como uma nova dialéctica do comportamento e do meio, descritivamente constatada na nossa experiência". ${ }^{12} \mathrm{E}$, de facto, a ordem humana parece construir novas estruturas entre acção e meio percebido, igualmente colando estes termos com a mesma forte correlação dialéctica que antecede a respectiva consideração separada. Refere-se Merleau-Ponty, antes de mais, à correlação entre um tipo específico de acção (o trabalho) e uma situação nova percebida (povoada de "objectos de uso" e de "objectos culturais" 13 ) que leva às ultimas consequências a estrutura formada por "aptidão" e "meio", ou seja, que desvenda em profundidade a mistura, a relação intrínseca, a homogeneidade, o entrelaçamento entre o agir sobre o meio e a consciência, o trabalho e a percepção.

A percepção, "em particular", ${ }^{14}$ enquanto participa da estrutura total do sujeito concreto, deve ser, então, remeditada a partir da sua inserção nessa correlação onde "aptidão", "significação" e "meio percebido" se unificam. Ensinamentos preciosos a este respeito podem ser retirados da descrição minuciosa da percepção nascente na criança - dessa capacidade perceptiva ingénua que lentamente esquecemos ao sobrepor-lhe os hábitos intelectuais da manipulação teórica. A criança, de facto, não começa por perceber o mundo como conjunto de dados puros e isolados, frontalmente presentes a um olhar desinteressado; aquilo que primeiro percebe - os outros corpos humanos - é primeiro percebido como "centros de expressão" ${ }^{15}$ e não como conjunto de traços sensí-

${ }^{9}$ SC, p. 174

${ }^{10} S C$, p. 175

"SC, p. 141.

${ }^{12}$ Bimbenet, E. La structure du comportement. Chap. III, 3 -L'ordre humain. Merleau-Ponty. Paris: Ellipses, 2000, p. 32.

${ }^{13}$ Cf. SC, p. 175-176.

${ }^{14} S C$, p. 175

is SC, p. 181. 
veis determinados. É mais tarde que esquecemos ou tendemos a esquecer que a expressividade do corpo de outrem (com as intenções que visa) é manifestação mais "rigorosa" da sua realidade do que a cor dos olhos ou a distância mensurável entre o nariz e o queixo. A seguir, a criança percebe o envolvimento prático do seu corpo "através de determinados objectos de uso". ${ }^{16}$ Tal relação prática é medida de uma pertença corporal a um mundo que desenrola e é desenrolado por intenções humanas, não se reduzindo, portanto, a um conjunto de meros objectos exteriores indiferentes. Finalmente -terceira categoria estrutural da percepção da criança-, o mundo é percebido pela criança no esboçar da linguagem que, longe de ser trabalho de conceptualização ideal, está primeiro também ao serviço do comércio prático e intencional mantido entre o corpo e o mundo. ${ }^{17}$

Expressividade do corpo de outrem, objectos manipulados, palavra escutada (e mimeticamente reutilizada), não são originariamente conhecidos como objectos verdadeiros; são, isso sim, vividos pela criança como realidades familiares. O ensinamento desta distinção é decisivo: há que reabilitar essa verdade da intenção humana eminentemente perceptiva que desvenda a realidade do mundo para aquém das manipulações objectivantes, esse modo de perceber autêntico e alternativo aos saberes construídos por perspectivas de sobrevoo, mas que inusitadamente faz plena justiça aos fenómenos do mundo - a esses fenómenos que parecem dispostos a mostrar parte ou facetas da sua realidade, apenas ocultando-se como objectos no encontro promovido pelo corpo perceptivo.

Alguns "estados da consciência adulta", segundo Merleau-Ponty, permitem compreender o que está aqui em questão. Veja-se para tanto o exemplo do jogador de futebol em acção: ${ }^{18}$ durante uma partida, o terreno de jogo não é para ele um "objecto" idealmente representado, mas uma "realidade" povoada por "linhas de força" (os flancos, os corredores), por "sectores" (o ataque, a defesa, o meio-campo), por áreas, por "posições" (em losango, em quadrado), que reclamam de cada jogador um determinado modo de acção em cada momento e em cada oscilação desse jogo de intensidades espaciais. Para o jogador, o terreno não é um dado, mas uma "realidade presente como o termo imanente das suas intenções práticas; o jogador faz corpo com ele" ${ }^{19}$ e sente cada direcção, cada linha de força, cada sector do espaço como direcção, linha de força ou sector expressivo do seu próprio corpo. Cada manobra desse corpo activo modifica, por seu turno, o terreno de jogo, nele introduzindo novas linhas de força com renovados equilíbrios e desequilíbrios, novas cartografias de áreas

${ }^{16} S C$, p. 181: «On pourrait être tenté de dire qu'après le corps humain, ce sont les objets d'usage crées par l'homme qui composent le champ de la perception.»

17 Cf. SC, p. 185: «Il faut que le langage entendu ou ébauché, l'apparence d'un visage ou celle d'un objet d'usage soient d'emblée pour l'enfant l'enveloppe sonore, motrice ou visuelle d'une intention significative venue d'autrui.» 
recompostas pelas quais a acção se realizará e o "campo fenomenal" ${ }^{20}$ será de novo jogado. O exemplo é significativo: a percepção original é um saber do espaço; mas não do espaço objectivo. Perceber dependerá menos da posição de um sujeito ante um objecto numa extensão mensurável, do que do pacto secreto - e mais antigo do qualquer discurso - que as disposições perceptivo-motoras do corpo mantêm com um espaço cuja realidade fundamental apenas se desvenda quando vivida.

Ora, para avançar neste sentido, certamente que a descrição empírica de acções como a do futebolista não é suficiente. Para aquém da descrição empírica, uma descrição fenomenológica ${ }^{21}$ é requerida, pois o que está em questão é bem mostrar a que ponto "o aspecto descritivo da percepção no seu começo exige uma reforma da noção de consciência". ${ }^{22}$

\section{Fenomenologia do espaço vivido}

Considerando o modo como a criança percebe o rosto de alguém, "é impossível aplicar-lhe a célebre distinção da forma a priori e do conteúdo empírico". ${ }^{23}$ Devemos reconhecer, isso sim, a existência de "a priori materiais" 24 e, em consequência, deixar de definir a consciência como "uma função universal de organização da experiência que imporia a todos os seus objectos as condições da existência lógica e da existência física", ou como uma "actividade mental" e "princípio de todas as coordenações". ${ }^{25}$

A consciência, em cada situação de correlação perceptiva, nada é senão adesão completa aos contextos perceptivos, devendo, finalmente, ser desvendada como lugar ${ }^{26}$ onde o mundo tem lugar: mais do que "sujeito epistémico", a consciência é antes "rede de intenções significativas, ora claras para elas próprias, ora ao contrário vividas mais do que conhecidas". ${ }^{27}$ Ela não é mera

${ }^{20} S C$, loc. cit.

${ }^{21}$ Veja-se o importante capítulo quarto da obra em análise. Sublinhamos a seguinte passagem à qual voltaremos: «Pour marquer à la fois l'intimité des objets au sujet et la présence en eux de structures solides qui les distinguent des apparences, on les appellera des 'phénomènes' et la philosophie, dans la mesure où elle s'en tient à ce thème, devient phénoménologie, c'est-à-dire un inventaire de la conscience comme milieu d'univers.» (SC, p. 215). Interessante notar que o lugar importante da fenomenologia fora já antevisto no relatório intitulado "La Nature de la Perception", com o qual, em 1934, Merleau-Ponty procedeu ao balanço do primeiro ano da investigação traçada pelo projecto de trabalho de 1933 a que aludimos no início deste trabalho (cf. PP,pp. 20 ss.)

$22 S C$, p. 183.

$23 S C$, p. 185.

${ }^{24} S C$, p. 186.

${ }^{25} S C$, loc. cit.

${ }^{26}$ Recorde-se $S C$, p. 215; cf. nota supra n. 23.

${ }^{27} S C, 187$. 
capacidade abstracta de representação face a um agir cego, antes participa globalmente da vida do sujeito e das suas respectivas estruturas concretas de acção. Descobrimos assim uma consciência constitutivamente perceptiva, ou seja, feita de um corpo vivo, motor, activo, ${ }^{28}$ intencional e polarizador dos eventos que desenrolam o mundo tal como existe. Ora, dar conta do que assim entra em jogo, exige uma radicalização dos instrumentos teóricos disponibilizados pela psicologia da gestalt. Tal desiderato será prosseguido por Merleau-Ponty, ao longo de uma efectiva fenomenologia da percepção ${ }^{29}$ que se espera capaz de dar conta dessa consciência corporalizada que é milieu do universo ${ }^{30}$. Uma fenomenologia da percepção será, assim, tarefa de descrição rigorosa do entrelaçamento entre o "sujeito" activo que percebe e o mundo que está para ser percebido.

Não é uma empreitada pequena, já que exige, desde logo, uma necessária releitura da própria empresa fenomenológica tal como desenhada por Husserl. As tensões descortinadas no interior do projecto do mestre alemão serão, para Merleau-Ponty, particularmente férteis. Veja-se o caso da "redução fenomenológica" que Husserl apresentou como "regresso a uma consciência transcendental", ante cujo poder de constituição eidética o mundo "se desvelaria numa transparência absoluta"; ${ }^{31}$ os constantes recomeços e reformulações da questão são reveladores do que, para Merleau-Ponty, deve entender-se ser o principal ensinamento da redução fenomenológica: "a impossibilidade da redução completa". ${ }^{32}$ Consequentemente, urge notar que a atitude natural nunca deixa verdadeiramente de se insinuar no âmbito da consciência reduzida. Presentes no mundo e não puros espíritos, reflectimos sempre sobre um irreflectido que nos encontra a nós, e não que nós possamos construir. As essências, por seu turno, se são o desejo legítimo de "recuar aquém do nosso comprometimento para o fazer aparecer ele próprio como espectáculo", não poderão então ser o

${ }^{28}$ Tal é verdade, recorde-se, quando a criança vê na expressividade de um rosto uma intenção colada à fisionomia; tal é ainda verdade tratando-se dos objectos de uso como da palavra. A percepção nascente, como vimos com o exemplo da criança, não funciona por constatações de conteúdos indiferenciados de um lado e de intenções humanas que se lhe viriam somar através de uma síntese fruto da cultura e da educação, por outro. A percepção, no seu começo, obriga antes a considerar o surgimento de significados intimamente ligados aos dados sensíveis e decifrados pré-conceptualmente pelo modo de ser corpo

${ }^{29}$ Merleau-Ponty, M., Phénoménologie de la perception, Gallimard, Paris, $1945(=P h . P)$

${ }^{30}$ Cf. uma vez mais, $S C$, p. 215 . Ver supra nota 23 . Atente-se no título do capítulo quarto de onde se retira a referência. A inspiração fenomenológica cruza-se com a história do problema alma/corpo, onde avúltam os nomes de Descartes, Malebranche, Biran, ou Bergson (Merleau-Ponty, M., L'union de l'âme et du corps chez Malebranche, Biran et Bergson. Paris: Vrin, 1968). Dir-se-ia que o modo de apropriação merleau-pontyano da fenomenologia implica uma aclimatação ou mútuo cruzamento com uma tradição antiga e tipicamente francesa de pensar o corpo - como se a fenomenologia pudesse vir esclarecer possibilidades da tradição reflexiva, e esta ajudar a libertar possibilidades do horizonte fenomenológico.

${ }^{31}$ Ph.P, p. V.

${ }^{32}$ Ph.P, p. VIII. 
último verdadeiro que procuramos e para aquém do qual não podemos recuar; esse último - que se trata justamente de tentar compreender-, não é senão o "comprometimento efectivo" num mundo para nós "antes de qualquer tematização". ${ }^{33}$ Neste sentido, a consciência é bem vínculo ao mundo. Mas se é assim intencional e permanece ligada àquilo de que é consciência, deve ser porque ela própria se encontra realmente comprometida no mundo - para o qual não cessa de ser vocação e do qual não deixa de acolher a constante e imperiosa solicitação; ${ }^{34}$ será, pois, intencional na exacta medida em que for perceptiva, perceptiva na exacta medida em que for corpo e corpo na exacta medida em que habitar o espaço como justa contrapartida do modo como este naquele se pronuncia infatigavelmente.

Nesse habitar ${ }^{35}$ joga-se uma primeira abertura às coisas, sem a qual nenhum conhecimento objectivo seria possível; ${ }^{36}$ esse habitar é, pois, essencialmente espacial. O contacto entre corpo e espaço é, num certo sentido, a base que torna possível compreender como ganha sentido a experiência do mundo que somos. ${ }^{37}$ Uma fenomenologia da percepção terá assim, desde logo, como tarefa dar conta da vertiginosa proximidade ${ }^{38}$ sincronizada que ocorre originariamente entre as disposições perceptivo-motoras do sujeito que percebe e um espaço que solicita a co-respondência corporal, entre um corpo que -diríamos assim - o espaço torna espacializante e um espaço que o corpo torna corporalizador. ${ }^{39}$

Explicitemos esta imagem regressando ao exemplo da percepção de um rosto, que Merleau-Ponty retoma na Phénoménologie: perceber um rosto não é "formar a ideia de uma certa lei de constituição que o objecto observaria invariavelmente em todas as suas orientações possíveis, é ter sobre ele um certo domínio, poder seguir na sua superfície um certo itinerário perceptivo"; mas - acrescenta logo de seguida -, tal poder de adoptar um certo itinerário perceptivo, depende sempre de uma "certa orientação das coisas". ${ }^{40} \mathrm{E}$ tal orien-

${ }^{33}$ Ph.P, p. X.

${ }^{34}$ Ph.P, p. XIII.

${ }^{35}$ Ph.P, p. 162

${ }^{36}$ Ph.P, p. 113

${ }^{37}$ Cf. Ph.P, loc. cit.: «Être une conscience ou plutôt être une expérience, c'est communiquer intérieurement avec le monde, le corps et les autres, être avec eux au lieu d'être à côté d'eux.»

3.8 Proximidade, recorde-se, que nos impede de nos concebermos como puro espírito separado das coisas, mas apenas como consciência perceptiva, logo, como corpo; proximidade que nos impede, enfim, de definir as coisas como puros objectos sem atributo humano, já que incrustado como corpo activo no mundo, nunca as coisas invadem o sujeito perceptivo como estranhas, mas já sempre trazendo a manifestação significativa -e fenoménica- do próprio modo pelo qual o mundo aparece, na sua própria aparição, para o corpo.

${ }^{39}$ Cf., por exemplo, Ph.P, p. 237: «La chose et le monde me sont donnés avec les parties de mon corps, non par une "géométrie naturelle", mais dans une connexion vivante comparable ou plutôt identique à celle qui existe entre les parties de mon corps lui-même.»

${ }^{40}$ Ph.P, pp. 292-293. 
tação "não é um certo carácter contingente" das coisas percebidas; é o "meio pelo qual eu a[s] reconheço e dela[s] tenho consciência" ${ }^{41}$ como corpo. A contrapartida de estar no espaço como corpo parece ser, pois, em certa medida pelo menos, a justa co-respondência ao modo como as coisas, envolvendo o corpo, ensinam - ante-predicativamente - a perceber. Semelhante encontro - pelo qual os poderes do corpo desposam e são desposados pelo mundo, pelo qual o projecto geral de mundo albergado pelo corpo se harmoniza com todas as situações possíveis de mundo - é tanto do corpo como do espaço. ${ }^{42}$ Não certamente encontro entre um corpo objectivo, colocado no mundo como mais um objecto a uma distância determinada de outros, e um espaço geometricamente mensurável, entendido à maneira clássica como extensão homogénea e tridimensional inalterada pela deslocação dos objectos; tal encontro tece-se no ajustamento da dimensão vivida do corpo ${ }^{43}$ e da lógica vivida ${ }^{44}$ do espaço: eis a que ponto é "uma existência espacial a condição primordial de toda a percepção". ${ }^{45}$

Merleau-Ponty não se enganou ao reconhecer no corpo vivido a inscrição de um saber antigo do espaço, traçado no tecido de uma enigmática intencionalidade prática: o corpo vivo desenrola o espaço e é desenrolado por ele, pela sua constelação significante, pelo modo como.os fenómenos - aquém da distinção da forma e do conteúdo, ${ }^{46}$ - se parecem organizar para o corpo. Se o corpo conhece à sua maneira e de avanço o mundo não é certamente de modo gnosiológico ou representativo, mas primeiro através de uma secreta e riquíssima praktognosia, ${ }^{47}$ pela qual desvenda a sua "situação" como sinónimo de uma essencial adesão e equivalência pré-pessoal (anónima) à forma geral do mundo. O "situar-se" do corpo é um entregar-se dinâmico - um ir até às coisas que é, antes de mais, um responder ao modo como as coisas vêm até nós e nos demandam. O modo de pertença activa do corpo ao coração do espaço deve, pois, contribuir para que algo seja percebido, já que traça itinerários que concorrem para que um arranjo momentâneo das partes do mundo, uma vez reunidas, sustente uma experiência perceptiva. "Se aproximo de mim o objecto - exemplifica Merleau-Ponty - ou se o faço girar entre os meus dedos para o 'ver melhor', é porque cada atitude do meu corpo é imediatamente para mim poder de um certo espectáculo, que cada espectáculo é para mim o que ele é numa certa atitude kinestésica" ${ }^{48}$ - atitude que, acrescente-se, estrutura o espaço

${ }^{41}$ Ph.P, p. 293

${ }^{42}$ Cf. $P$ h.P. pp. 281 ess.

${ }^{43}$ Ph. P, p. 90

${ }^{44}$ Ph.P, p. 61

${ }^{45}$ Ph.P, p. 127.

${ }^{46}$ Cf. Ph.P, p. 287.

${ }^{47} \mathrm{Ph} . \mathrm{P}$, p. 164: «L'expérience motrice de notre corps n'est pas un cas particulier de connaissance; elle nous fournit une manière d'accéder au monde et à l'objet, une "praktognosie" qui doit être reconnue comme originale et peut-être comme originaire.»

${ }^{48}$ Ph.P, p. 349 
por meio de uma claridade que "ilumina o seu caminho", 49 Há na percepção um sentido definido pelo movimento do corpo: o percebido é originariamente o visado pela motricidade corporal. Com propriedade se pode, então, afirmar que a motricidade é a intencionalidade original: ${ }^{50}$ : o movimento de "entrada" do corpo no mundo define-a como essencial não-coincidência, incompletude, abertura, excesso, pertença ao interior do espaço. Enraizada num corpo preso ao aparecer do mundo, a consciência não mais se poderá definir como esfera de imanência ou gesto de sobrevoo; outrossim, ela será outro nome de um modo de ser corpo definido como "unidade aberta", "expressividade recíproca das partes" que deve reconhecer-se "exactamente correlativa dessa unidade aberta e não tematizável, unidade de estilo mais do que de significado, que caracteriza o mundo". 51

O corpo no espaço é bem uma inesperada obra de arte: "ele é um nó de significações vivas e não a lei de um certo número de termos co-variantes". ${ }^{52}$ Escusado será afirmar que o movimento do corpo não é apenas uma deslocação objectiva; nele, intenção e realização, propósito e efectuação, consciência (perceptiva) e motricidade são uma e a mesma coisa; o movimento do corpo espacializado - movimento de um "sujeito" que está todo no exterior ${ }^{53}$ - é movimento de sentido, sendo que este, pelo que fica dito, exige do espaço que se prolongue pelo corpo e o trespasse, e do corpo que seja capaz de se virtualizar, se desapossar pelos horizontes da intensidade do espaço.

A fenomenalidade do espaço, por seu turno, não resultará primeiro de um qualquer sistema de determinações objectivas, antes se encontrando anichado na experiência do movimento corporal do sentido como sua face outra. A situação do corpo é uma contrapartida do espaço que se desvenda real quando "entre o meu corpo como potência de certos gestos, como exigência de certos planos privilegiados, e o espectáculo percebido como convite aos mesmos gestos e teatro das mesmas acções, se estabelece um pacto que me dá a fruição do espaço como às coisas poder directo sobre o meu corpo". ${ }^{54}$ Assim se plasma, como condição de possibilidade, cada um dos meus comportamentos perceptivos. "A série das nossas experiências, até à primeira, trans-

49 Cf. Barbaras, R., Le désir et la distance, ed. cit., p. 115.

50 Ph.P, p. 160: «Ces éclaircissements nous permettent enfin de comprendre sans équivoque la motricité comme intentionnalité originale.»

51 Cf. Barbaras, R., «De la phénoménologie du corps à l'ontologie de la chain», in Goddard, J.-Ch., Le corps, Paris: Vrin, 2005, p. 227. Texto editado também em Barbaras, R., Le tournant de l'expérience. Recherches sur la philosophie de Merleau-Ponty. Paris: Vrin, 1998, pp. 95-136.

52 Ph.P, p. 117: «C'est en ce sens que notre corps est comparable à l'œuvre d'art. Il est un nœud de significations vivantes et non pas la loi d'un certain nombre de termes covariants.»

${ }^{53}$ Ph.P, p. V.

${ }^{54}$ Ph.P, p. 289. 
mitem uma espacialidade já adquirida" 55 - e é ela "que permite perceber" ${ }^{56}$ O espaço orientado do corpo é, certamente, uma parte do espaço objectivo; deve no entanto entender-se que tal espaço apenas se percebe quando esburacado, rasgado pelo espaço orientado do corpo que lhe restitui a direita e a esquerda, o alto e o baixo, o leve e o pesado; mas - e este "mas" é particularmente importante - o corpo apenas assim parece desenrolar o espaço, como justa contrapartida do modo como antepredicativamente o espaço o solicita, ${ }^{57}$ o desdobra, solta, abre, invade, desapropria, espalha e, apenas assim, contribui para a sua situação. A questão é bem, pois, a de levar às últimas consequências essa bizarra evidência de um espaço que se percebe no modo de ser do corpo, de um espaço que sobre o qual, antes de se ter consciência, já nos fez ser a sua consciência. Cézanne tinha razão: a paisagem pensa-se em mim e eu sou a sua consciência. ${ }^{58} \mathrm{E}$ J. Paulhan também não se enganou ao falar, num sentido análogo, de um "espaço sensível ao coração".59 Mas que sentido fenomenológico albergam tais afirmações?

O célebre exemplo do cubo, ao qual Merleau-Ponty recorre por diversas vezes, parece a este propósito significativo. Ao considerá-lo na Phénomenologie Merleau-Ponty cedo conclui da pertença do olhar à mesmidade pré-objectiva ou unidade transitiva de cada objecto no espaço. Tal possibilidade, que reclama uma efectiva époché das concepções que ora objectivam, ora intelectualizam o espaço, traz consigo toda uma nova ideia de fenómeno que se oferece como coexistência, e uma nova ideia de espacialidade que, articulada com o conceito fenomenológico de "campo visual", permite concluir que as dimensões espaciais se organizam como relações estruturais referidas a um sujeito perceptivoaquele que sabe acolher e seguir as indicações de tal campo. Tal possibilidade, que radica numa experiência primordial da espacialidade - na memória de um imemorial do espaço - reclama as ideias de "enraizamento" num "dentro" não sobrevoável e não objectivável; e, neste sentido, devem tecer-se necessariamente de "estruturas de horizonte", já que nesse "dentro" o perceptível não é nunca uma totalização, adequação, ou coincidência plena, mas antes capacidade de seguir em cada presença o que se presentifica apenas como impresentável. Ora, o espaço no qual tal aparecer se pode sustentar deve revelar como

${ }^{55}$ Ph.P, p. 293.

${ }^{56}$ Cf. Ph.P, loc. cit.

${ }^{57}$ Cf. Ph.P, p. 161: «La conscience est l'être à la chose par l'intermédiaire du corps. Un mouvement est appris lorsque le corps l'a compris, c'est-à-dire lorsqu'il l'a incorporé à son 'monde', et mouvoir son corps c'est viser à travers lui les choses, c'est laisser répondre à leur sollicitation qui s'exerce sur lui sans aucune représentation.»

${ }^{58}$ Merleau-Ponty, M., «Le doute de Cézanne», in Merleau-Ponty, M., Sens et non sens. Genève: Nagel, 1966, p. 30 (=SNS).

${ }^{59}$ Cf. Merleau-Ponty, M., Causeries. 1948. Paris: Seuil, 2002, p. 22 (=C). 
principal dimensão a mais existencial: ${ }^{60}$ a profundidade ${ }^{61}$ - bizarra dimensão que, em rigor, longe de assinalar distintamente cada objecto, "aparece com toda a evidência ao ponto de vista e não às coisas", ${ }^{62}$ que longe de se deixar encerra em cálculos de distância, desdobra um "estar à distância" que, paradoxalmente, nunca apresenta a distância como dado. É na teia desta dimensão do espaço que está incrustado aquele que percebe - num "dentro", portanto, que é mistura de mim nas coisas e das coisas em mim, viagem entre a figura e o fundo, mais do que delimitação precisa dos lugares que eu ocupo em relação às coisas.

Tais considerações - Merleau-Ponty sabe-o bem - permanecerão estranhas a todas as doutrinas clássicas que, sob o primado de uma geometrização abstracta e axiomática, perseguem uma ideia de espaço infinito, homogéneo, isotrópico, onde, necessariamente, "o sujeito abandona [...] o seu lugar, o seu ponto de vista sobre o mundo e passa [...] a pensá-lo numa espécie de ubiquidade". ${ }^{63}$ Em tal contexto, a profundidade nada guarda de problemático, sendo tendencialmente explicada em termos de intervalos crescentes ${ }^{64}$ e larguras calculadas. Esquecem tais perspectivas, no entanto, que qualquer tentativa de construção racional do espaço tende a promover o desmembramento do campo perceptivo, e a supor o espaço como imediatamente objectivo, quando, na verdade, tal depende de um processo lento de formalização ou depuração de tudo o que é estranho ao geométrico. Cézanne viu-o bem ao rebelar-se contra a perspectiva clássica associada à "pirâmide visual", e assente em esquemas de constância e medida que obnubilam a experiência originária da espacialidade. Descobre, desse modo, como escreve Merleau-Ponty,

o que a mais recente psicologia devia formular. A perspectiva vivida, a da nossa percepção não é a perspectiva geométrica ou fotográfica: na percepção, os objectos próximos parecem mais pequenos, os objectos afastados maiores [...]. Dizer que um círculo visto obliquamente é visto como uma elipse é substituir à percepção efectiva o esquema que deveríamos ver se fossemos aparelhos fotográficos: vemos, na realidade, uma forma que oscila ao redor da elipse sem ser elipse. $^{65}$

E algumas páginas mais à frente conclui-se:

A coisa tal como é vivida não é encontrada ou construída a partir dos dados dos sentidos, mas oferece-se globalmente como o centro a partir do qual irradiam. ${ }^{66}$

${ }^{60}$ Barbaras, R., De l'être du phénomène. Sur l'ontologie de Merleau-Ponty. Grenoble: Millon, 1991, p. 238.

61 Ph.P, p. 296.

62 Ph.P, loc. cit.

${ }^{63}$ Ph.P, p. 295.

${ }^{64}$ Cf. Ph.P, p. 296-297; 301.

65 SNS, p 24.

${ }^{66} S N S$, loc. cit. 
Em rigor, o pintor, quando olha, não percebe objectos separados mas conjuntos. Se pinta não é, pois, porque objectiva mas porque reúne "um sentido espalhado nos fenómenos e [...] diz [...] o que eles querem dizer-deles mesmos". ${ }^{67}$ É assim que responde ao nascer da profundidade sob o seu olhar, outro modo de dizer o aparecer de um espaço que, através das ligações das coisas entre si e através do sujeito perceptivo, dirigem e orientam o corpo como se procurassem ensiná-lo a ver. Será a essa orientação que consegue co-responder um olhar "viajante", mergulhado no tecido da profundidade e capaz de acompanhar cada coisa no seu excesso, no seu escorregar para todas as outras. Porque é bem de um tecido ou teia que se trata: teia formada pelas coisas que não estão localizadas mas criam localizações, que desenrolam o espaço ou "espessura de um médium sem coisa" 68 que, anisotópica e inhomogeneamente, polariza um "ser-em-redor-de-mim" e um "ser-através-de-mim" que o corpo perceptivo acolhe e percorre activamente - apenas assim, eis o decisivo, chegando a perceber. Neste sentido, a "posição" do sujeito perceptivo também não pode equivaler a estar no ponto do espaço objectivo que o corpo ocupa; ao invés, como escreverá Merleau-Ponty, a "nossa inserção no espaço é sempre indirecta, reflectida para nós pelo aspecto perspectivístico das coisas que indica o ponto que deve ser o nosso". ${ }^{69} \mathrm{O}$ que não é dizer pouco: compreender algo no espaço depende, em última análise, da capacidade do corpo se submeter às orientações do espectáculo que o convocam obsessivamente e, desse modo, pode dizer-se, chegam a contribuir para o espacializar.

É pois necessário que o olhar se consiga perder pelo tecido que solda cada coisa "nos seus arredores"; é pois requerido que o corpo seja trespassado, desapossado, tornado anónimo para chegar a estar situado e poder perceber. Esta é uma possibilidade da profundidade do espaço - de um espaço conhecido desde sempre pelo corpo, de um espaço familiar, que me permite aceder à verdade das coisas porque estou ancorado nele. Longe de ser algo que esteja entre os objectos avaliando distâncias, a profundidade está no meio, quase fantasmagoricamente ${ }^{70}$ como afastamento que não cava distâncias, ou seja, como o próprio modo das coisa infra-geometricamente se emaranharem entre si, se impregnarem umas das outras, se entrelaçarem mutuamente, criando uma textura capaz de revelar o corpo perceptivo a si mesmo como um dos fios desse mesmo recíproco entrecruzamento. $\mathrm{O}$ tecido da espacialidade subverte qualquer ruptura, qualquer quebra entre quem vê e o que é visto. Mas que significa isto exactamente?

${ }^{67}$ Ph.P, p. 305.

${ }^{68}$ Ph.P. p. 308.

${ }^{69}$ Merleau-Ponty, M.,«Éloge de la philosophie», Merleau-Ponty, M.Éloge de la philosophie et autres essais. Paris; Gallimard, 1971, p. 27.

${ }^{70}$ Cf. Ph.P, p. 308. 


\section{Ontotopologia da Profundidade}

Se é verdade o que fica dito, um derradeiro aprofundamento da reflexão é, então, requerido. O primado fenomenológico da consciência e da relação sujeito/objecto, ao qual permanecem presas as análises da Phénoménologie, criam uma sombra de impensado que importa libertar. Pressentimo-la na tensão evidente que percorre este texto entre, por um lado, a ideia fenomenológica de uma consciência que é sempre consciência de alguma coisa e, por outro, o facto evidente de tal consciência ser intencional na medida em que é convocada, atravessada, descentrada, por aquilo de que é consciência. Pela orientação daqueles primados, o percebido é directamente todo o ser percebido; pela evidência do segundo, o ser percebido não só não se reduz ao percebido, como é mesmo o facto de em muito o extravasar que parece permitir que algo se perceba no corpo perceptivo. Merleau-Ponty viu bem esta tensão e a necessidade de radicalizar a análise no sentido de uma investigação renovada do ser percebido.

Armado de um "método indirecto", dedicar-se-á, então, o filósofo a procurar evidências de uma noção de ser que não se limita às capacidades per- . ceptivas de discriminação do arranjo fenoménico do mundo. Vemo-lo ensaiar tal caminho, desde logo, nas férteis análises do problema da linguagem, em cuja dimensão criativa ${ }^{71}$ vislumbra a não coincidência com a tradução directa de qualquer particularidade experienciada; indirectamente, por meio de "torções expressivas impostas às palavras", a linguagem é capaz de comunicar o carácter único e silencioso de qualquer experienciar e dẹmonstrar que não há acesso directo ao ser, que é indirectamente que nos relacionamos com ele, que as condições de inteligibilidade estão do seu lado (o que algumas palavras comprovam ao iluminarem subitamente um pouco da filigrana do mundo). Nas notas das aulas no Collège de France, dedicadas ao tema da "passividade" 72 vemos também que, ao analisar os fenómenos do sono, dos sonhos, do inconsciente e da memória, ${ }^{73}$ Merleau-Ponty reconhece demonstrado que a actividade consciente é apenas uma parte de um campo mais vasto que a interpela eficazmente $^{74}$ a partir de zonas que, por excesso, não coincidem com a correlação perceptiva. Tal reconhecimento de estruturas passivas parece, então, sugerir a necessidade de aprofundamento de uma nova reflexão ontológica ${ }^{75}$ capaz de

71 Cf. Merleau-Ponty, M.,La prose du monde. Paris: Gallimard, 1969. A redacção do texto data de 1951-52.

72 Cf. Merleau-Ponty, M.,L'institution. La passivité. Notes de cours au Collège de France (1954-1955), Belin, 2003 (=IP).

73 Cf. IP, pp. 157 ss.

74 Cf., por exemplo, IP, p. 158: «Si je dis que je suis tout conscient de ce passé [psychanalytique], non enveloppé par lui, je lui refuse l'essentiel.»

${ }^{75}$ Cf. IP, p. 178: «Pourquoi l'ontologie phénoménologique est mal comprise? Que faire pour la développer? Parce que nous sommes pris dans ontologie objectiviste et découvrons le perçu comme résidu.» 
dar conta de um mundo - e, consequentemente, de um espaço - que sustenta (e, por isso, permanece irredutível à totalização) a percepção. A necessidade dessa nova reflexão ontológica parece também demonstrada, em contraluz, pelas "oscilações" ou impasses, ao longo dos quais se escreveu - de Santo Agostinho a Sartre passando, nomeadamente, por Descartes, Kant ou Husserl ${ }^{76}$ - uma história da ideia de natureza ${ }^{77}$ que nunca foi capaz de tornar predominante uma concepção de natureza fáctica, cuja produtividade estivesse apta a sustentar os poderes subjectivos. Vários desenvolvimentos da ciência contemporânea - em muito diferentes dos da ciência clássica que, limitando-se a manipular os factos, se recusava a habitar o mundo ${ }^{78}$-, parecem indicar o justo caminho a trilhar. No domínio da física, por exemplo, e nomeadamente no campo da mecânica quântica, aprendemos, por um lado, que pelo menos ao nível sub-atómico a probabilidade é constitutiva do ser, ${ }^{79} \mathrm{e}$, por outro, que espaço é "polimorfo" 80 (admitindo várias métricas) e o tempo não é indiferente nem aos fenómenos, nem ao ponto de vista do observador. ${ }^{81}$ No campo da microfísica confirmamos que as coisas percebidas não são núcleos de ser determinados, mas modulações de um campo polimorfo que se organiza em eventos prováveis que se podem individuar pela intervenção subjectiva, ${ }^{82}$ mas de modo nenhum coincidir na sua totalidade com ela. Haverá assim, como bem viu Whitehead, ${ }^{83}$ que ponderar uma ideia de natureza que alberga uma "actividade própria" e cuja ordenação desdobra uma espacialidade e uma temporalidade próprias ${ }^{84}$ que, em derradeira análise, é o espaço-tempo do próprio mundo natural do qual o corpo "participa" como corpo vivo.

O campo das ciências biológicas guarda igualmente indicações importantes que apoiam esta nova via de reflexão. Atente-se, por exemplo, nas demonstrações do mimetismo: ${ }^{85}$ estas já comprovaram haver entre animais e meio ambiente a organização de uma "sensibilidade patencial" que os entrelaça na virtualidade de uma teia coesa. ${ }^{86}$ Cada ser vivo parece incluir, no seu modo de existir no mundo natural, a referência a uma camada potencial de ser: ele encontra-se organizado como ser sensivel por referência a uma sensibilidade

${ }^{76}$ Cf. Merleau-Ponty, M.,La Nature. Notes de cours du Collège de France. Paris: Seuil, 1994, pp. $27-58(=N)$.

77 Cf. $N$, loc. cit.

78 Merleau-Ponty, M.,L'CEil et l'esprit, Gallimard, Paris 1964, p. 9 (=CE).

79 Cf. $N$, p. 132 ss.

${ }^{80} N$, p. 144: «L'espace perceptive est polymorphe. Le champ perceptif nous offre le première modèle de l'Être sur lequel la science travaille afin de donner une vision articulée de l'Être.»

${ }^{81}$ Cf. $N$, p. 139 ss.

${ }^{82} \mathrm{~N}$, pp. 187-259.

${ }^{83}$ Cf. $N$, p. 153 ss.

${ }^{84} \mathrm{~N}, 155-165$

${ }^{85} \mathrm{~N}$, p. 240

${ }^{86}$ Cf. N.pp. 263 ss. 
iminente que o vai convocando e, assim, desenvolvendo as potencialidades. E que cada corpo vivo seja corpo sensível no meio de outros corpos sensíveis partilhando a mesma teia virtual, deve, finalmente, ser verdade para o próprio corpo perceptivo humano. O que não é dizer pouco: um corpo activo que é também sensível, é um corpo que, justamente, mais do que arbitrar o modo como as coisas lhe aparecem sem se confundirem com ele, é um corpo que "sabe" poder a todo o momento trocar de lugar com as coisas que ofazem sensivel. Se quiséssemos ilustrar tal tese com o célebre exemplo do corpo tocante-tocado, diríamos que, mais do que ser capaz de tocar e se sentir tocado, mais do que ser ora activo, ora passivo ${ }^{87}$ (como é ainda o caso na Phénoménologie), o corpo sensível deve ser entendido como aquele que ao tocar "se torna o tocado" e ao ser tocado "se torna o tocante" 88 - ou seja, que ao contactar com algo mais do que a sua própria massa, fecha o seu círculo sobre o sensível exterior que não é senão o topos da sua verdadeiro sensibilidade.

A ser assim, o ponto de apoio da consciência, tal como é ainda assumido na Phénoménologie, deve efectivamente ser radicalizado, já que o índice último de uma consciência essencialmente incarnada deve definir-se por um excesso em direcção a um mundo englobante e, por isso, intotalizável - excesso que, assim, é mais das próprias coisas e da teia invisivel que as sustenta do que é da consciência. O que urge pensar é bem, pois, a que ponto são as coisas que nos têm e não nós que temos as coisas. ${ }^{89}$ Se o poder do corpo de ir até às coisas é um poder sensível, é porque a sensibilidade inerente ao mundo o faz corpo sensível. Deste modo, a intencionalidade prática desvendada pela Phénoménologie não encontra o seu sentido derradeiro a partir da reflexividade corporal; tal capacidade perceptiva é, outrossim, sustentada pela organização, pela teia ou camada sensível partilhada por todos os corpos sensíveis e todas coisas. Dito de outro modo: não é por um corpo vivo ter comportamentos perceptivos que algo se percebe (por restrição do ser ao ser percebido) na sua realidade; é porque o mundo natural é essencialmente sensivel que pode ser perceptivamente percebido por um ser que pertence a esse mundo.

Em suma, há que reconhecer que as coisas partilham um mesmo estofo que o corpo e, por isso, se revelam aos poderes exploratórios activos deste último. O corpo não é sensível porque se sente ou sente as coisas; é sensível porque depende e participa da camada sensível - carnal-onde as coisas, e o corpo por entre elas, se encontram unidos.

${ }^{87}$ Cf. Ph.P, p. 108: «Le corps [touchant-touché] se surprend lui-même de l'extérieur en train d'exercer une fonction de connaissance, il essaye de se toucher touchant, il ébauche "une sorte de réflexion" et cela suffirait pour le distinguer des objets, dont je peut bien dire qu'ils 'touchent' mon corps, mais seulement quand il est inerte, et donc sans jamais qu'ils le surprennent dans sa fonction exploratrice.»)

$88 N$, p. 285.

${ }^{89}$ Merleau-Ponty, M., Le Visible et l'Invisible. Paris: Gallimard, 1964, p. 247: «A savoir que les choses nos ont, et que ce n'est pas nous qui avons les choses.») $(=V I)$. 
Em derradeira análise, a intencionalidade do corpo perceptivo encontra sempre muito mais do que meros objectos: encontra algo de que a visão, o toque, a motricidade, fazem parte: encontra reversibilidade, empréstimo, promiscuidade, quiasma mais antigo do que qualquer operação ou acto do pensamento; encontra uma membrana, uma folha do ser que faz com que seres, natureza, homem, sejam uns nos outros. ${ }^{90}$ Impossível se torna supor que tal textura do sensível coincida com o sujeito perceptivo; este é apenas mais um dos seus fios e a possibilidade de ter uma perspectiva sobre o mundo radica, precisamente, no facto de se encontrar incrustado numa teia que o excede radicalmente. Dito de modo mais claro: o ser sobreleva necessariamente o ser percebido. Merleau-Ponty já o havia suspeitado ao estudar o nível da ontogénese animal: a coesão do organismo refere-se a uma totalidade "invisível", ${ }^{11}$ latente, que extravasa mesmo qualquer percepção possível. É essa ideia de ser que se desprende da demonstração científica, ainda que a ciência só por si não seja capaz de dar conta dela, ${ }^{92}$ que é "necessário deslindar" ${ }^{93}$ filosoficamente: a ideia de um ser onde "Seres, Natureza e homem" estejam juntos do lado do nada, não certamente de um nada prévio, mas de uma negatividade operante que cruza todo o visível.

Há, pois, que desvendar a textura última que garante essa estranha coexistência ou co-naturalidade, essa urdidura onde todas as coisas existem de perto "deslizando umas nas outras" 94 e através do corpo; há que dar conta desse "conjunto concreto de uma maneira de ser geral [...] que traz consigo um estilo de ser por todo o lado onde se encontra uma parcela"; 95 enfim, há que reconhecer essa "unidade genética do Ser". Neste sentido, a experiência do corpo "tocante-tocado" deve ser retomada, mas a partir de uma reflexividade mais fundamental que é a do próprio Sensível; a própria ideia de que algo aparece à consciência deve, igualmente, ser entendida a partir da ideia de "abertura de uma dimensão", de acolhimento de "estruturas, membranas estrelas da vida que são as coisas". Estas, então, gravitam à nossa volta,${ }^{96}$ num excesso de proximidade que faz da percepção "relativa impercepção de um horizonte ou de um fundo que ela implica mas não tematiza", ${ }^{97}$ relativa "possibilidade no sentido de pregnância, envolvimento de um actual inacessível num actual acessível". ${ }^{98}$

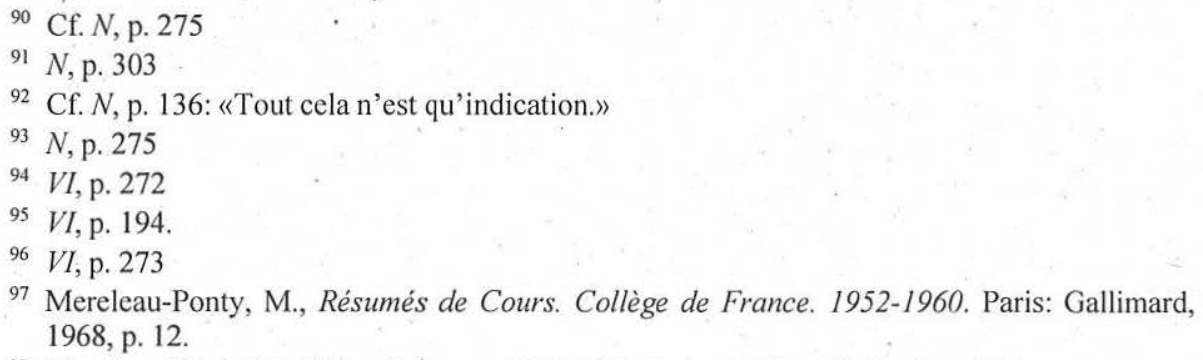

${ }^{98}$ Mereleau-Ponty,M., Notes de cours. 1959-1961. Paris: Gallimard, 1996, p. 167. 
Percepcionar, neste contexto, deverá, então, significar reunir um sentido espalhado dos fenómenos, "dimensionalizar" no sentido de acompanhar a integração de cada coisa numa constelação onde nada aparece isolado, mas organizado no interior de um "Ser tecido de negação". Finalmente, o corpo que se empresta, se entrega, se desapossa, se espalha pelo mundo, fá-lo como justa contrapartida do modo como o mundo toma o corpo a cargo e, trespassando-o livremente, exercendo-o, inspirando-o, respirando nele, procura chegar à expressão do seu próprio sentido. Eis o sentido derradeiro de um corpo que é "entrelaçamento de visão e movimento" 99 imbricado num visível cruzado de invisível. "Ter um lugar" de onde ver, significa, então, ser espalhado, virtualizado, pelo espaço que orienta e dirige o olhar numa coesão, na qual sempre se ignorará onde um e outro começam e acabam.

A própria noção de espaço reclama, enfim, um aprofundamento ontológico: há que encetar uma elucidação última dessa pertença do interior do corpo ao exterior do espaço e do interior do espaço ao exterior do corpo, do visível do espaço ao seu invisível através da dobra do corpo - numa palavra da textura da profundidade de que é feito necessariamente o tecido do interior dinâmico do Sensível.

O caminho de Merleau-Ponty é conhecido: desvendar a textura última de um espaço que é ordem da coexistência ou urdidura, onde todas as coisas existem de perto "deslizando umas nas outras", ${ }^{100}$ espaço que é "conjunto concreto de uma maneira de ser geral" 101 que traz consigo um estilo de ser por todo o lado onde se encontra uma parcela", espaço que é profundidade em cada "clarão de mundo", que se desdobra na "unidade genética do Ser" selvagem, que se fenomenaliza na carne do Sensível. Será desnecessário afirmar que "a carne não é matéria, não é espírito, não é substância" 102 mas sim, enquanto ser de indivisão prévio a todas as separações, a instância pré-egológica que garante a promiscuidade de tudo em tudo. Instância que é, então, o lugar "da inauguração do onde e do quando". ${ }^{103}$ Tese decisiva: quando Merleau-Ponty atribui à sua ontologia a tarefa de "redefinir o vidente o mundo visto", ${ }^{104}$ e medita, nesse contexto, o corpo como variante notável desse elemento que funda derradeiramente o onde e o quando, ${ }^{105}$ é também do eșpaço que se trata - de um espaço desvendando a partir de uma textura carnal, a única que permite compreendê-lo, radicalmente, como profundidade, ou seja, como "experiência da reversibilidade das dimensões", como "localidade' global", como "volumino-

\footnotetext{
99 E, p. 16.

100 VI, p. 272.

101 VI, p. 194.

$102 V I$, p. p. 184.

103 VI, p. 184.

$104 V I$, p. 108.

${ }^{105} V I$, p. 184.
} 
sidade" que exprimimos numa palavra dizendo que a coisa está lá", ${ }^{106}$ como "a deflagração do ser". ${ }^{107}$

É a profundidade assim entendida que Cézanne não cessou de procurar, ${ }^{108}$ essa animação resplandecente ${ }^{109}$ do visível, essa densidade do campo visual formado pela organização das coisas que se ocultam parcialmente umas às outras. E este é bem o enigma da profundidade do espaço - do que, sem se reduzir a planos definidos ou distâncias mensuráveis, está "entre", sustentando, sem se ver, o esgueire de cada coisa em direcção a todas as outras. No recuo invisível sob cada presença carnal, joga-se, de facto, a densidade espacial de uma espessura partilhada - espaço que não promove uma identidade ou fusão, mas prolonga uma mesma membrana, desperta uma mesma "visibilidade secreta" 110 , na qual se acendem as faíscas do quiasma que anima o Sensível. O olhar nasce desse fundo mais englobante de visibilidade, nasce por segregação da Carne à qual continua aberto - mas aberto no sentido em que dela é variante peculiar: carne da carne, o corpo mais não é do que o lugar onde visível se dobra sobre si para ser vidente, o tocável para ser tocante- enfim, onde o Ser se dobra para ser expressão. Pintar, neste sentido, mais do que falar do espaço, é um "deixar falar o espaço". Mais do que ser a consciência da paisagem que se pensa em mim, devo afirmar que "literalmente o próprio espaço se sabe através do meu corpo". ${ }^{111}$ Ora, é apenas nesse momento, nesse gesto, o corpo ganha algo como a sua "situação". Estar situado é ser espacializado pelo espaço."12 Eis o que resta considerar.

Porque é isto que nos parece ser essencial: "estar no espaço" recebe um sentido derradeiro como enraizamento ou pertença à própria relação endo-ontológica que "reflecte a minha incarnação e da qual eu sou a contrapartida".113 A ser assim, toda uma nova topologia está, pois, por pensar: uma endo-onto-topologia capaz de dar conta da espacialidade inerente a um corpo que é dobra da própria deiscência do vidente em visível e do visível em vidente, ${ }^{114}$ logo, também nó da deiscência do espaço espacializante em espaço espacializante-espacializado. Neste contexto, é a própria noção de profundidade que, em

\footnotetext{
106 E, p. 65.

$107 \mathcal{C}$, loc. cit.

108 Cf. $E$, p. 64.

109 Cf. $C$, p. 71.

110 E, p. 22.
}

111 Merleaú-Ponty, M., «Le philosophe et son ombre», in Merleau-Ponty, M., Éloge de la philosophie et autres essais, ed. cit., p. 257.

112 Cf. por exemplo $C E$, p. 74: "Cheminant dans l'espace, elle ronge cependant l'espace prosaïque et le partes extra partes, elle développe une manière de s'étendre activement dans l'espace qui sous-tend aussi bien la spatialité d'une chose que celle d'un pommier ou d'un homme.»)

113 Merleau-Ponty, M., «Le philosophe et son ombre», art. cit., p. 258.

114 Cf. $V I$, p. 201. 
derradeira análise, se revela como a "unidade por transcendência": 115 aquela de que o "traço do pintor - a linha flutuante- ou o varrer do pincel é a evocação peremptória". ${ }^{116}$ Menos do que uma "terceira dimensão" do espaço presa à órbita da objectividade, a profundidade carnal é dimensão que mistura todas as outras. Num certo sentido é bem o nome da filigrana do visível, onde nenhuma coisa é observável em si, mas visível porque alberga, em invisível -como possibilidade ou latência -,a presentificação de todas as outras. "Quando digo que o visível é invisível [...] -esclarece Merleau-Ponty a este propósito- quando digo que ver é ver mais do que aquilo que se vê, isso não deve ser compreendido como contradição, é a própria visibilidade que comporta uma não-visibilidade" 117 - outro modo de dizer o Ser polimórfico ou de Indivisão sempre em vias de Fenomenalização. A profundidade é o seu tecido.

Assim se compreende por que razão, para Cézanne, o "arranjo das cores" ou as "deformações coerentes" eram tão importantes: tratava-se de expressar um espaço que se organiza em profundidade, ou seja, que é iminente atmosfera ilocalizável, reversibilidade co-extensiva, onde cada coisa está apta a tornar-se marca ou emblema de parte total. Assim se dá notícia do espaço inaugural entretecido na própria verticalidade do Sensível: espaço onde cada evidência de não-determinação guarda uma possibilidade ontológica, enquanto abertura de uma dimensão ou nivel. Por isso dissemos que a percepção é sempre relativa impercepção. Entende-se agora a que ponto o é: tal não se deve a qualquer excesso de distância que perderia as coisas na indistinção do longínquo; igualmente, de modo algum se trata de propor um em-si invisível; outrossim se afirma um excesso de proximidade, que obriga a concluir estar em cada olhar implicada a concomitante confirmação da pertença originária daquele que vê ao mesmo Ser. Por isso, também - percebemos agora radicalmente - é o princípio de inscrição do corpo no espaço a despossessão ou o anonimato: o corpo é um fio da Carne, através do qual se dobra ou enrola o poder de irradiação, de mistura, de mescla, de reversibilidade, de imbricamento, de deiscência, de visibilidade e invisibilidade do Sensível. No espaço, o corpo é, pois, esse lugar de uma ontológica esquizofrenia: forçado a viajar pelo visível, é ao mesmo tempo irresistivelmente convocado a ser dobra do invisivel latente em cada coisa percebida.

E se afirmámos que as coisas ensinavam a ver, tal tem um sentido ontológico preciso no contexto da radical viragem anti-antropocêntrica que a nova ontologia reclama: é a fenomenalização do Ser, no jogo de cruzamentos entre visibilidade e invisibilidade, que, no seu próprio centro, descobre no corpo a sua própria face tocante-tocada, vidente-visível. No momento em cada coisa ganha carne e desenrola o espaço, o corpo - também - é igualmente espacializado; não porque ganhe um qualquer lugar determinado, mas porque redobra

$115 N C$, p. 169.

116 VI, p. 261.

$117 V I$, p. 300. 
a profundidade ou dimensionalidade do espaço, porque se empresta à própria distância entre o fenomenal (sensível, visível) e o não-fenomenal (insensível, invisível), porque está preso ao próprio quiasma de tudo em tudo que anima o Sensível. E se tal acontece - eis a nossa tese - não é senão porque o próprio movimento do Ser é espacializante, ou seja, não termina sem situar intra-ontologicamente o corpo como nó ou dobra do visível e do invisível, do tocante e do tocado, do espacializante e do espacializado. Já sempre carne da carne, sempre em si e nas coisas, em si e nos outros, o corpo é, pois, igualmente nó da espacialização do espaço, cujo movimento não se encerra sem o espacializar entre as duas folhas de cada coisa e do mundo. A situação do corpo no espaço é, portanto, da ordem da pertença à profundidade que sitúa na medida em que deslocaliza, des-subjectiviza, virtualiza, desapossa e imbrica.

O olhar do pintor sempre traçou os seus caminhos na profundidade desse espaço sem quebras, capaz de nos colocar "em nós e nas coisas, em nós e no outro, ao ponto em que, por uma espécie de quiasma, nos tornamos outros e nos tornamos mundo". ${ }^{118} \mathrm{E}$, de facto, profundidade oferecida à profundidade, não somos nós capazes de "tocar o sol, as estrelas [...] estar ao mesmo tempo em todo o lado, tão perto do que está longe como do que está perto". ${ }^{119}$ Eis o enigma de um espaço espacializante, outro nome para a "relação a ele mesmo do visível que me atravessa e me constitui como vidente, círculo que eu não faço mas me faz, enrolamento do visível sobre o visível", ${ }^{120}$ que não termina sem fazer do corpo dobra ou momento-lugar espacializado da espacialização do espaço.

No mesmo momento em que espaço se sabe através do meu corpo, só apenas então, ganha o corpo um lugar: o da pertença conivente ao que guarda o segredo da sua radical plasticidade.

\section{ABSTRACT}

In our paper we aim to meditate on the concept of depth (profondeur) in the works of M. Merleau-Ponty, as it is a key notion to understand the French philosopher's concept of space. Furthermore we will try to show that space plays a fundamental role in the development of Merleau-Ponty's philosophy, allowing us to understand important features both of his phenomenological readings and ontological project. 
